\title{
Osteopenia in extremely low birthweight infants
}

\author{
A HORSMAN, ${ }^{*} \mathrm{~S}$ W RYAN, $\uparrow$ P J CONGDON, $\uparrow \mathrm{J}$ G TRUSCOTT, ${ }^{*}$ AND J R JAMES $\ddagger$ \\ ${ }^{*}$ MRC Bone Mineralisation Group, Department of Medical Physics, †Regional Neonatal Surgical and \\ Intensive Care Unit, and $\ddagger$ University Department of Paediatrics, Clarendon Wing, The General Infirmary, \\ Leeds
}

SUMmaRY Fifteen extremely low birthweight (ELBW) white infants (those weighing $1000 \mathrm{~g}$ or less) were observed at birth, within eight weeks of birth and near 40 weeks postconception. On the second and third occasions, weight, crown-heel length, and bone mineral content of their forearms were measured. Fifteen infants born at full term on whom similar measurements were made soon after birth acted as controls. Between 32 and 39 weeks the median weight of ELBW infants increased from $970 \mathrm{~g}$ to $1850 \mathrm{~g}$ and crown-heel length from $35.7 \mathrm{~cm}$ to $41.0 \mathrm{~cm}$. There was no evidence, however, of bone mineral accretion in the measurement region; initial and final median measurements of bone mineral content were $76 \mathrm{mg} / \mathrm{cm}$ and $86 \mathrm{mg} / \mathrm{cm}$, the median individual difference being only $4 \mathrm{mg} / \mathrm{cm}$ with an interquartile range of $25 \mathrm{mg} / \mathrm{cm}$. Median weight, crown-heel length, and bone mineral content of the control group were $3270 \mathrm{~g}, 50.6 \mathrm{~cm}$, and $196 \mathrm{mg} / \mathrm{cm}$, respectively. Compared with the controls, ELBW infants at 39 weeks were a median (interquartile range) of 1420 (525) g lighter, $9.9(3.9) \mathrm{cm}$ shorter, and had a bone mineral content deficit of $108(32) \mathrm{mg} / \mathrm{cm}$.

In terms of weight and crown-heel length ELBW infants at 39 weeks were comparable with infants born and observed at 32 weeks' gestation; compared with these infants the bone mineral content deficit in the ELBW group was about $33 \%$.

It has been shown that in neonates the bone mineral content of the radius and ulna can be measured precisely and accurately by single photon absorptiometry. ${ }^{1-5}$ Using that technique we have shown that there is a substantial deficit in bone mineral content in most preterm infants when they reach a postconceptional age of 40 weeks compared with infants born at full term who were observed at birth. $^{2}$

Such a deficit may be the result of reduced density of mineralisation caused by a low rate of mineral accretion on existing organic matrix, or by a reduction in bone size caused by impaired skeletal growth, or a combination of the two. The relative contribution of each factor to undermineralisation in preterm infants is unknown, but has important implications for the assessment and treatment of osteopenia of prematurity. There is evidence, for example, that reduced rates of mineral accretion can be improved by mineral supplementation, ${ }^{3}$ and that radiographically detectable undermineralisation can be ameliorated by vitamin $\mathrm{D}$ supplementation. ${ }^{6}$ In contrast, reduced bone growth tends to be associated with reductions in general measurements of growth such as the rates of increase of body weight and crown-heel length, which may reflect inadequate nutrition in general.

To assess the relative contributions of a reduction in the density of mineralisation and bone size to the known bone mineral content deficit in preterm infants at 40 weeks, we studied a series of extremely low birthweight (ELBW) infants (those weighing $1000 \mathrm{~g}$ or less) who as a group were expected to have a more severe degree of undermineralisation than larger infants. ${ }^{7}$

\section{Patients and methods}

Parental consent was obtained to carry out the investigations in every case and the study had the approval of the local hospital ethics committee.

\section{PRETERM ELBW INFANTS}

Fifteen preterm white infants (eight of whom were boys) of birth weight $1000 \mathrm{~g}$ or less were recruited over a three year period. Gestational ages were calculated from maternal menstrual history and where possible were confirmed by either external 
examination ${ }^{8}$ or by ophthalmoscopic examination of the lens (table 1). ${ }^{9}$ Gestational ages ranged from 25 to 30 weeks. Birth weights ranged from 650 to $1000 \mathrm{~g}$, and were appropriate for gestational age in all but two cases, cases 2 and 5 .

In all cases the bone mineral content $(\mathrm{mg} / \mathrm{cm})$ was measured within eight weeks of birth at the middle of the right forearm by photon absorptiometry. ${ }^{12}$ The amount of radiation was small, the skin entry dose being $0.03 \mathrm{mGy} /$ investigation. Postconceptional ages at that time ranged from 29 to 35 weeks; weight (g) and, except in one case, crown-heel length $(\mathrm{cm})$ were measured just before the scan. Between 37 and 42 weeks after conception, the ELBW infants' weights, crown-heel lengths and bone mineral contents were measured again (tables 2 and 3 ).

CONTROLS GROUP BORN AT FULL TERM

Fifteen white infants born at full term were identified from our existing database to serve as controls. Each one had had measurements of weight, crownheel length, and bone mineral content carried out within one week of birth and could be matched with an ELBW infant, the matching variable being post-

Table 1 Sex, gestational age at birth, and weight of the matched pairs of ELBW and control infants born at full term

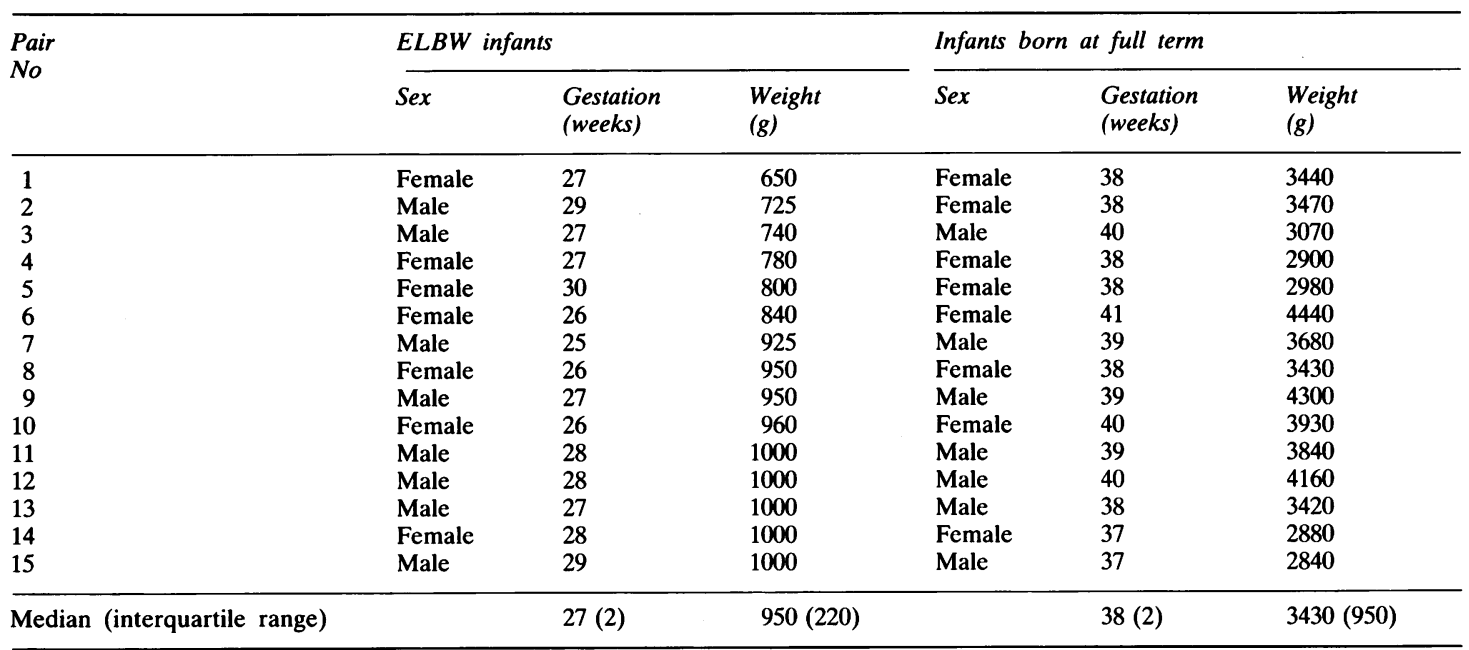

Table 2 Postconceptional age, weight, crown-heel length, and bone mineral content of the ELBW infants on the first occasion that absorptiometry was carried out

\begin{tabular}{llccc}
\hline $\begin{array}{l}\text { Case } \\
\text { No }\end{array}$ & $\begin{array}{l}\text { Postconceptional } \\
\text { age (weeks) }\end{array}$ & $\begin{array}{l}\text { Weight } \\
(\mathrm{g})\end{array}$ & $\begin{array}{l}\text { Crown-heel } \\
\text { length }(\mathrm{cm})\end{array}$ & $\begin{array}{l}\text { Bone mineral content } \\
(\mathrm{mg} / \mathrm{cm})\end{array}$ \\
\hline 1 & $30 \cdot 43$ & 700 & $33 \cdot 1$ & $75 \cdot 58$ \\
2 & $30 \cdot 29$ & 675 & $33 \cdot 4$ & $58 \cdot 81$ \\
3 & $34 \cdot 71$ & 970 & $37 \cdot 0$ & $72 \cdot 01$ \\
4 & $34 \cdot 00$ & 1025 & $35 \cdot 0$ & $60 \cdot 99$ \\
5 & $33 \cdot 43$ & 1050 & $36 \cdot 2$ & $96 \cdot 54$ \\
6 & $30 \cdot 14$ & 800 & $35 \cdot 6$ & $72 \cdot 11$ \\
7 & $29 \cdot 00$ & 910 & $35 \cdot 2$ & $75 \cdot 27$ \\
8 & $31 \cdot 86$ & 950 & $38 \cdot 2$ & $71 \cdot 62$ \\
9 & $30 \cdot 57$ & 975 & $35 \cdot 3$ & $79 \cdot 69$ \\
10 & $29 \cdot 29$ & 825 & $39 \cdot 5$ & $106 \cdot 87$ \\
11 & $30 \cdot 71$ & 1000 & $35 \cdot 6$ & $79 \cdot 43$ \\
13 & $31 \cdot 43$ & 1100 & $38 \cdot 9$ & $89 \cdot 78$ \\
14 & $35 \cdot 00$ & 1250 & $37 \cdot 1$ & $75 \cdot 58(17 \cdot 98)$ \\
\hline Median (interquartile range) & $31 \cdot 14$ & 1000 & $35 \cdot 7(1 \cdot 9)$ & \\
\hline
\end{tabular}


Table 3 Postconceptional age, weight, crown-heel length, and bone mineral content of the ELBW infants on the second occasion that absorptiometry was performed, and of the control infants born at full term on the first occasion that absorptiometry was performed (soon after birth)

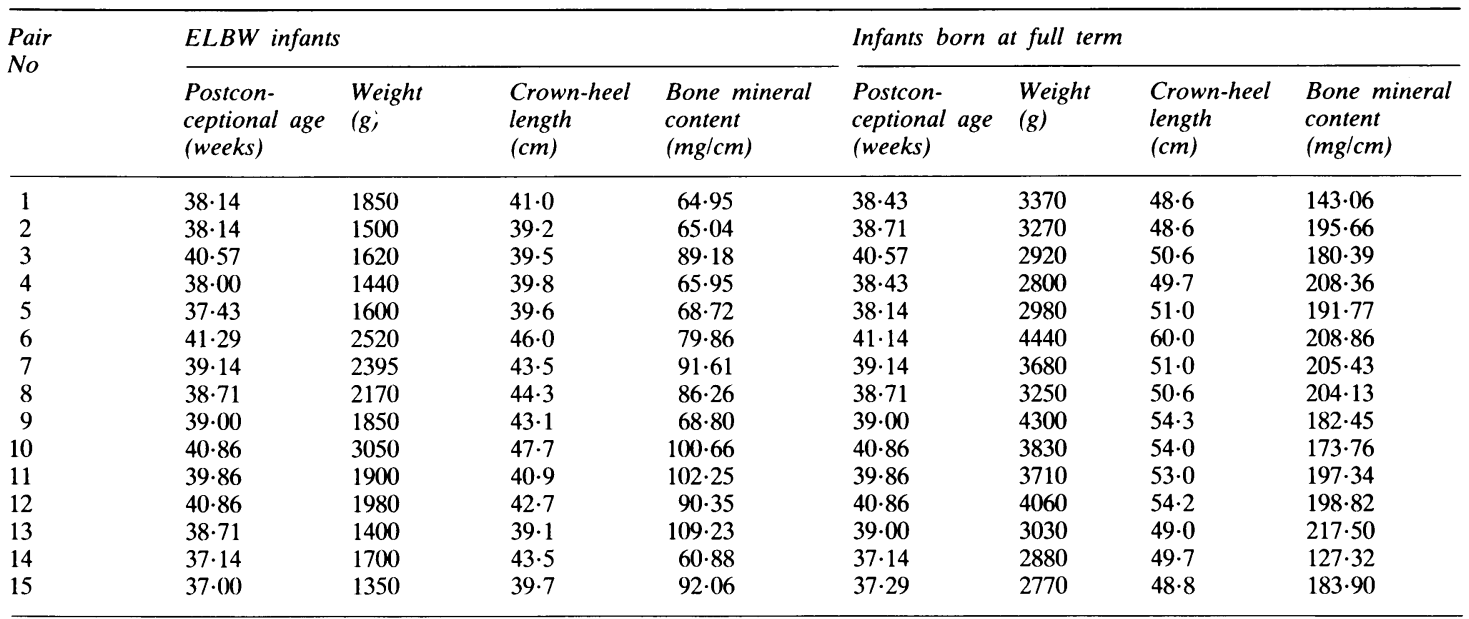

Median

(interquartile

conceptional age at the time the scan was performed; for the ELBW infant, this was the age at the second scan. Ages were matched to within one week and with one exception the pairs were matched for sex (tables 1 and 3).

\section{STATISTICAL ANALYSIS}

Non-parametric tests were used throughout. Null hypotheses that paired groups had common medians were tested using the Wilcoxon signed rank test. Rank correlation coefficients were compared using Spearman's test. Because we have shown that intrauterine growth curves for weight, crown-heel length, and bone mineral content are exponential, ${ }^{10}$ logarithms of the measurements were used to examine correlations between rates of change.

\section{Results}

\section{ELBW INFANTS}

In the interval between birth and the first scan (median (interquartile) $3.4(2 \cdot 7)$ weeks), the median weight gain $(\mathrm{g})$ in the ELBW infants was zero (interquartile range $270 \mathrm{~g}$ ). Thus at the time of the first scan the distribution of weights in that group was similar to the distribution of weights at birth.

The second scans were performed at a median postconceptional age of 38.7 weeks, the median (interquartile) time interval between the first and second scans being $7 \cdot 7(3 \cdot 7)$ weeks. During that time the median (interquartile) weight increase was 875 (770) $\mathrm{g}$ and the median crown-heel length increase was $4.85(4.60) \mathrm{cm}$; both increases were significant $(\mathrm{p}<0.01)$ and individual rates of weight and crownheel increase were significantly associated $(r=0.56$, $\mathrm{p}<0.05$; logarithmic data). Comparing the median increases with the median values at the time of the first scan, weight nearly doubled, and crown-heel length increased by $15 \%$. In contrast, the median (interquartile) change in bone mineral content between the two scans was only $3.56(24.68) \mathrm{mg} / \mathrm{cm}$, and was not significantly different from zero. There was no evidence in the data to suggest that the ELBW infants with the higher gestational ages at birth had mineralised their bones more rapidly than the remainder.

\section{DIFFERENCES AT 39 WEEKS BETWEEN ELBW INFANTS} AND THOSE BORN AT FULL TERM

The median (interquartile) values of postconceptional age at the time of second scan in the ELBW group and the time of the first scan in the control group were $38.7(2.6)$ weeks and $39.0(2 \cdot 1)$ weeks, respectively.

The ELBW infants were significantly lighter than those born at full term $(\mathrm{p}<0.01)$, the median difference between the pairs being 1420 (525) g. In the group born at full term the median weight was 
$3270 \mathrm{~g}$; the weight deficit in the ELBW group was therefore about $40 \%$. The ELBW infants were also significantly shorter $(p<0 \cdot 01)$, the median crownheel length difference between the pairs being 9.9 (3.9) $\mathrm{cm}$, about $20 \%$ less than the median crownheel length in those born at full term $(50.6 \mathrm{~cm})$. In the ELBW infants, there was significantly less mineral in the region scanned $(p<0 \cdot 01)$, the median difference in bone mineral content between the pairs being $108(31.84) \mathrm{mg} / \mathrm{cm}$; the median differences in bone mineral content was about $50 \%$ of that in those born at full term.

\section{Discussion}

Previous radiographic studies have shown disordered bone mineralisation in $75 \%$ of ELBW infants. ${ }^{7}$ We found severe osteopenia in all cases caused by an almost total failure of mineralisation from birth onwards; at about 39 weeks postconceptional age, every ELBW infant had a bone mineral content value below the lowest control value (127.32 $\mathrm{mg} / \mathrm{cm})$.

Because measurements of bone mineral content are influenced by density of mineralisation and by bone size, the osteopenia detected in the ELBW group might have been caused by a mineralisation defect alone, reduced linear growth alone, or a combination of the two. Our data have shown that retardation of growth did occur in a high proportion of the ELBW infants; 14 of the 15 infants at 39 weeks weighed less than the lowest control value $(2770 \mathrm{~g})$, and all had crown-heel lengths below the lowest control value $(48.6 \mathrm{~cm})$. As a group the ELBW infants at 39 weeks had weights and crownheel lengths similar to those of newborn infants of gestational ages of 32 weeks or less. Even such a profound reduction in growth rate, however, could not explain the observed mineralisation deficit observed at 39 weeks. The expected mean bone mineral content at birth for a group of infants of 32 weeks' gestation is $123 \mathrm{mg} / \mathrm{cm},{ }^{10}$ whereas the mean value in the ELBW infants at 39 weeks was 82.4 $\mathrm{mg} / \mathrm{cm}$ (median $86.3 \mathrm{mg} / \mathrm{cm}$ ), $33 \%$ less than expected. This deficit indicates what is commonly understood by the term 'metabolic bone disease' and it is this component that is probably shown on standard radiological assessment.

Our results therefore indicate that in ELBW infants osteopenia of prematurity detected by photon absorptiometry at about 40 weeks is caused both by reduced growth and by reduced density of mineralisation. It has previously been suggested that such osteopenia is the result of insufficient dietary intake of mineral, and that dietary mineral supplementation might normalise bone mineral content by the postconceptional age of 40 weeks. ${ }^{3}$ It is, however, clear from our results that in the most immature infants growth failure is an important factor in osteopenia at that time. Achievement of normal values of bone mineral content in ELBW infants requires not only successful mineral supplementation, but also successful stimulation of postnatal growth toward the rate achieved in utero.

SW Ryan was supported by a grant from the Special Trustees of The General Infirmary at Leeds, JR James held a research fellowship from the locally organised research fund of the Yorkshire Regional Health Authority, and JG Truscott and A Horsman were supported by the Medical Research Council. The authors thank Dr L Burkinshaw for his advice and guidance in the statistical analysis of the data.

\section{References}

1 James JR, Truscott J, Congdon PJ, Horsman A. Measurement of bone mineral content in the human fetus by photon absorptiometry. Early Hum Dev 1986;13:169-81.

2 James JR, Congdon PJ, Truscott J, Horsman A, Arthur R. Osteopenia of prematurity. Arch Dis Child 1986;61:871-6.

${ }^{3}$ Steichen JJ, Tsang RC. Osteopenia of prematurity; the cause and possible treatment. J Pediatr 1980;96:249-52.

${ }^{4}$ Chan GM, Mileur L, Hansen JW. Effects of increased calcium and phosphorus formulas and human milk on bone mineralisation in preterm infants. J Pediatr Gastroenterol Nutr 1986;5: 444-9.

5 Greer FR, Lane J, Weiner S, Mazess RB. An accurate and reproducible absorptiometric technique for determining bone mineral content in newborn infants. Pediatr Res 1983;17:259-62.

${ }^{6}$ Hillman LS, Hollis B, Salmons S, et al. Absorption, dosage and effect on mineral homeostasis of 25-hydroxycholecalciferol in premature infants. Comparison with 400 and 800 IU vitamin $D_{2}$ supplementation. J Pediatr 1985;106:981-9.

${ }^{7}$ Lyon AJ, McIntosh N, Wheeler K, Williams JE. Radiological rickets in extremely low birth-wcight infants. Pediatr Radiol 1987;17:56-8.

8 Parkin JM, Hey EN, Clowes JS. Rapid assessment of gestational age at birth. Arch Dis Child 1976;51:259-63.

9 Hittner HM, Hirsch NJ, Rudolph AJ. Assessment of gestational age by examination of the anterior vascular capsule of the lens. $J$ Pediatr 1977;91:455-8.

10 Ryan SW, Congdon PJ, James JR, Truscott J, Horsman A. Mineral accretion in the human fetus. Arch Dis Child 1988;63: 799-808.

Correspondence to Dr A Horsman, MRC Bone Mincralisation Group, Department of Medical Physics, The General Infirmary, Lceds LS1 3EX.

Accepted 1 December 1988 